\title{
A Review of Patient-Reported Outcome Data for Palliative Cancer Drugs Approved In the European Union
}

\author{
Borislav Borissov ${ }^{1 *}$, John DR Jolley ${ }^{2}$ \\ ${ }^{1} M D, P h D, M B A$, Prescriptia Ltd., Sofia, Bulgaria \\ ${ }^{2}$ Pharma Consult Global Ltd., London, UK
}

Received: January 28, 2018; Accepted: February 16, 2018; Published: February 22, 2018

*Corresponding author: Dr. Borislav Borissov, Prescriptia Ltd., 28 HristoBotev, Blvd., 1000 Sofia, Bulgaria, E-mail: borislav.borissov@ prescriptia.com

\begin{abstract}
Background: Results from patient reported outcome (PRO) are often undermined due to methodological issues thus limiting patient centeredness in clinical research for development of palliative cancer medicines.
\end{abstract}

Objective: The aim of this study was to identify the rate and type of PRO data included in the Summary of Product Characteristics (SmPC) for cancer palliative drugs approved in the European Union (EU) by December 21st 2017.

Results: From 115 approved cancer drugs, 6 or only $5.2 \%$ included PRO data in their SmPC about palliative cancer care, constituted by 4 international non-proprietary names (INNs) within 3 indications. Not all of them were used as a primary endpoint in the pivotal clinical trials.

Conclusion: The rate of PRO data included in the SmPC's of palliative cancer drugs approved in EU is very low and therefore all stakeholders should be encouraged to wider use of PRO tools in clinical research and development of palliative cancer medicines.

Keywords: Patient-reported outcomes; Cancer; Palliative drugs; Summary of product characteristics

\section{Background}

The Summary of Product Characteristics (SmPC) for medicinal products approved in the European union (EU) is the main public regulatory document, subject to approval by the regulatory authorities within the life cycle of a drug. The European Medicines agency (EMA) grants single marketing authorization for medicinal products in all $28 \mathrm{EU}$ member states as well as to the 3 countries from the European Economy Area (EEA). Both the Food and Drug Administration (FDA) and EMA have guidelines on the use and interpretation of subjective measurement scales. In the EMA's guideline related to the use of PRO measures in oncology studies, PRO is defined as "any outcome evaluated directly by the patient himself or herself and is based on patient's perception of a disease and its treatment(s). $P R O$ is an umbrella term covering both single dimension and multidimension measures of symptoms, HRQL, health status, adherence to treatment and satisfaction with treatment" [1].A patient- reported outcome (PRO) is defined by FDA as a "any report of the status of a patient's health condition that comes directly from the patient without interpretation of the patient's response by a clinician or anyone else" [2]. PROs are common tool for clinical evaluation of efficacy and quality of life in clinical research for chronic treatments such as palliative cancer care. PROs are also considered in Health Technology Assessment(HTA) models and included in the attributes of The HTA Core Model ${ }^{\circledR}$ (version 3.0) of the European network for HTA (EUnetHTA) - integrating a European vision of the best HTA practice [3]. Results from PROs however are often undermined due to methodological issues thus limiting patient centeredness in both clinical research and HTA. We hereby analyze PRO data included in the SmPC's of palliative cancer drugs approved by EMA.

\section{Methods}

All cancer drugs approved by EMA until December 21st 2017 were reviewed from the agency's website to check for indication/s eligible to be palliative based on the WHO definition for palliative care: "Palliative care is an approach that improves the quality of life of patients and their families facing the problem associated with life-threatening illness, through the prevention and relief of suffering by means of early identification and impeccable assessment and treatment of pain and other problems, physical, psychosocial and spiritual". After excluding withdrawn, suspended or refused applications, search continued for medicines which are not biosimilars, generics and other drugs without pivotal trials as well as vaccines and imagine- related drugs. The relevant SmPC section was reviewed for data derived from PRO tools. In addition, information was collected about each PRO tool, PRO endpoint status in the studies and the design of pivotal clinical trials where PROs were included. Descriptive statistics were performed in Microsoft Excel(C) 2016.

\section{Results}

From 115 European Public Assessment Reports (EPAR) for cancer drugs available, 10 drugs included palliative indications $(8.7 \%)$ and only $6(5.2 \%)$ met the inclusion criteria, constituted 

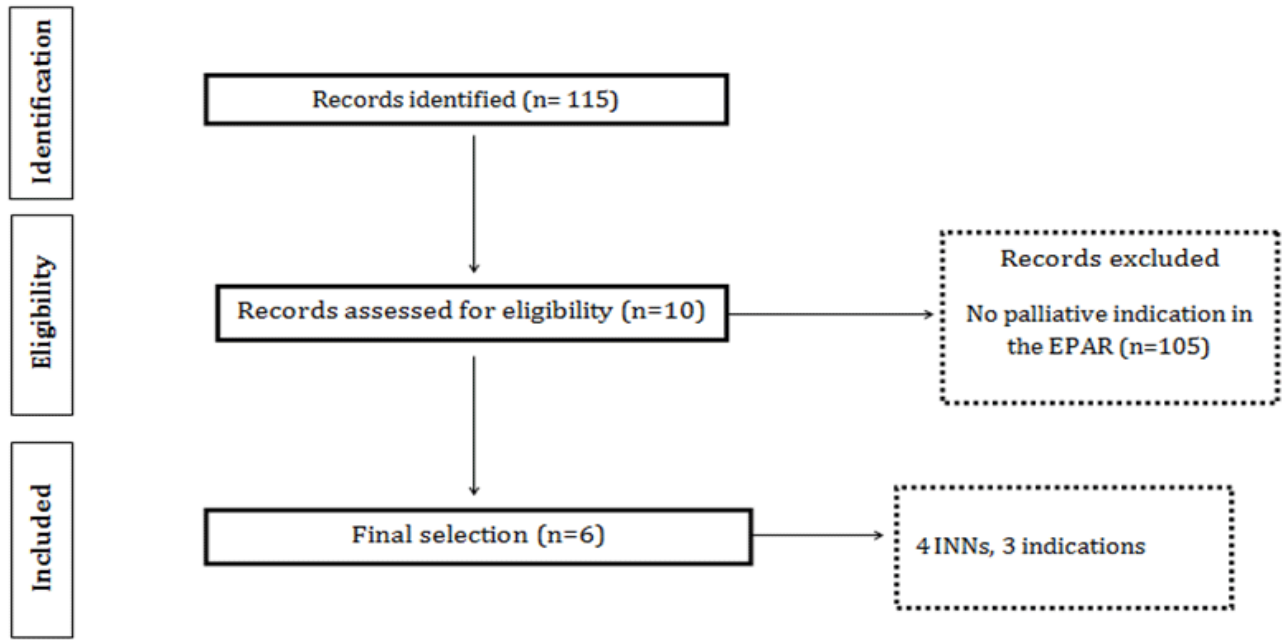

Figure 1: Diagram of the Search

Table 1: PRO data included in SmPC's for palliative cancer medicines approved by EMA

\begin{tabular}{|c|c|c|c|c|}
\hline INN & Indication & PRO Tool & PRO Endpoint Status & Trial Design \\
\hline $\begin{array}{l}\text { Darbepoetin } \\
\text { Alfa }\end{array}$ & $\begin{array}{l}\text { Anemia cancer patients } \\
\text { receiving } \\
\text { chemotherapy }\end{array}$ & $\begin{array}{l}\text { Fatigue scale } \\
\text { /FACT/ }\end{array}$ & Secondary & $\begin{array}{l}1 \text { randomized, double-blind, } \\
\text { placebo controlled trial }\end{array}$ \\
\hline $\begin{array}{c}\text { Fentanyl } \\
\text { /as citrate/ } \\
\text { Buccal tablets }\end{array}$ & $\begin{array}{c}\text { Treatment of } \\
\text { breakthrough pain /BTP/ } \\
\text { for chronic cancer pain }\end{array}$ & $\begin{array}{l}\text { Patient assessment of 11- } \\
\text { point scale pain intensity } \\
\text { /SPID60 and SPID 30/ }\end{array}$ & Primary & $\begin{array}{l}2 \text { randomized, double-blind, } \\
\text { placebo-controlled, crossover } \\
\text { trials. }\end{array}$ \\
\hline $\begin{array}{c}\text { Fentanyl } \\
\text { /as citrate/ } \\
\text { nasal spray solution }\end{array}$ & BTP for chronic cancer pain & SPID 30 & Primary & $\begin{array}{l}1 \text { randomized, double-blind, } \\
\text { placebo-controlled crossover } \\
\text { trial }\end{array}$ \\
\hline $\begin{array}{l}\text { Palonosetron } \\
\text { /as hydrochloride/ }\end{array}$ & $\begin{array}{l}\text { Acute nausea and vomiting in } \\
\text { emetogenic chemotherapy }\end{array}$ & $\begin{array}{l}\text { Complete response (No } \\
\text { Emesis and No Rescue) } \\
\text { Complete Control (Complete } \\
\text { Response no more than } \\
\text { Mild Nausea) } \\
\text { No Nausea (Likert scale) }\end{array}$ & Primary & $\begin{array}{l}3 \text { randomized double- blind } \\
\text { trials }\end{array}$ \\
\hline $\begin{array}{l}\text { Palonosetron } \\
\text { /as hydrochloride/ }\end{array}$ & $\begin{array}{l}\text { Acute nausea and vomiting in } \\
\text { emetogenic chemotherapy }\end{array}$ & $\begin{array}{l}\text { Complete response (No } \\
\text { Emesis and No Rescue) } \\
\text { Complete Control (Complete } \\
\text { Response no more than } \\
\text { Mild Nausea) } \\
\text { No Nausea (Likert scale) }\end{array}$ & Primary & $\begin{array}{c}3 \text { randomized double- blind } \\
\text { trials }\end{array}$ \\
\hline Rolapitant & $\begin{array}{c}\text { Nausea and Vomiting } \\
\text { in emetogenic cancer } \\
\text { chemotherapy }\end{array}$ & $\begin{array}{l}\text { Functional Living Index- } \\
\qquad \text { Emesis } \\
\text { /FLIE/ }\end{array}$ & Additional & $\begin{array}{c}1 \text { randomized, double-blind, } \\
\text { parallel group trial }\end{array}$ \\
\hline
\end{tabular}


by 4 international non-proprietary names (INNs) with granted in total 3 indications: anemia in cancer patients receiving chemotherapy /1 product/; treatment of breakthrough pain for chronic cancer pain / 2 products / and acute nausea and vomiting in emetogenic chemotherapy /3 products/ [Figure1].

All of them had 1 PRO tool, either from a single or from a composite method. For 4 drugs PRO was used as a primary endpoint in the pivotal trials, in 1 as a secondary and in 1 as additional endpoint / [Table 1].

Results from PROs used as primary end points were statistically significant. Where more than one drug were approved in the same therapeutic areas, PROs used were identical for chronic cancer pain and different in nausea/vomiting, while choice of PRO in this case was not justified. Another 4 drugs were approved for similar indications without PRO data and therefore not analyzed.

\section{Discussion and Conclusions}

Results reveal surprisingly low rate of approved palliative cancer drugs and a far too low rate of PRO data included in the SmPC's. Indeed, oncology products may not support PROs likely because of logistical hurdles and/or study design [4] but PRO use is more frequent in clinical trials of products for chronic, disabling conditions where the goal of treatment is not curing but rather an improvement in symptoms, functioning, or quality of life [5]. Low rate of PRO data in the main regulatory document - the SmPC in Europe - may well be one of the reasons why these important measures of patient satisfaction and cost-effectiveness are often under-used in daily practice $[6,7]$.

There may be different reasons for the low rate of PRO use in palliative care designated medicines. One of them is the low number of dedicated PRO instruments available and the lack of tools specific to the condition. This is a well- known problem in rare diseases and orphan drugs too [8]. It appears that typical health- related quality of life (HRQoL) methods are replaced with less complex tools -example with the five-point Likert scale to evaluate nausea compared to the validated 40 -item quality of recovery (QoR-40) scale consisting clinically relevant dimensions [9]. Low rates of collection of PROs in pivotal clinical trials in palliative treatments are potentially underpinned by the lack of regulatory requirements that mandate the inclusion of PRO endpoints in drug development and validated methodologies. There is a need to increase use of PRO data in drug research for palliative cancer care. And there are incentives on the way. In EU calls for policy changes in HTA models are rising. Recent $\mathrm{EU}, \mathrm{WHO}$ and others findings highlight inconsistency, variability and lack of predictability in the current HTA value frameworks urging authorities to encompass all attributes recommended by the EUnetHTA Core Model $\AA$ where patient perspective, including PRO, should be considered[10-19].

There are a number of limitations in this analysis. The search inclusion and exclusion criteria were chosen subjectively and limited to least possible indications. As palliative care is not standard regulatory term some medicines may also be claimed to be eligible, i.e. drugs for prevention of bone fractures in cancer patients. Finally, the results of this analysis are not generalizable to cancer drugs other than the listed with a similar regulatory profile as described herein.

In conclusion, the rate of PRO data included in the SmPC's of palliative drugs approved in EU/EEA is very low. There is a need to encourage all stakeholders for wider use of PRO tools in both clinical research and HTA as patient centeredness in this therapeutic area is especially challenging and sensitive.

\section{Compliance with Ethical Standards}

Authors declare that no funding was received to conduct the research presented here.

\section{Ethical approval}

This article does not contain any studies with human participants or animals performed by any of the authors.

\section{References}

1. European Medicines Agency (EMA). Appendix 2 to the guideline on the evaluation of anticancer medicinal products in man. The use of patient-reported outcome (PRO) measures in oncology studies. 2016

2. Food and Drug Administration. Guidance for Industry on Patientreported Outcome Measures: Use in Medical Product Development to Support Labeling Claims. Food and Drug Administration Federal Register. 2009; 1-30.

3. EUnetHTA. HTA Core Model®. National Institute for Health and Welfare.

4. Gnanasakthy A, DeMuro C, Clark M, Haydysch E, Ma E, Bonthapally V. Patient-Reported Outcomes Labeling for Products Approved by the Office of Hematology and Oncology Products of the US Food and Drug Administration (2010-2014). J Clin Oncol. 2016; 34(16):19281934; Doi: 10.1200/JC0.2015.63.6480

5. Gnanasakthy A, Mordin M, Clark M, DeMuro C, Fehnel S, CopleyMerriman C. A Review of Patient-Reported Outcome Labels in the United States: 2006 to 2010. Value Health. 2012; 15(3):437-442; Doi: 10.1016/j.jval.2011.11.032

6. Mott FE. Patient Reported Outcomes (PROs) as Part of Value-Based Care Can Shape Therapy Guidelines: Impact on Emerging Targeted Agents and Immunotherapy Protocols in Resource-Limited Regions. Oncol Ther. 2017; 5(1):69-74; Doi: 10.1007/s40487-016-0038-7

7. Brundage M, Bass B, Davidson J, Queenan J, Bezjak A, Ringash J, et al. Patterns of reporting health related quality of life outcomes in randomized clinical trials: implications for clinicians and quality of life researchers. Qual Life Res. 2011; 20(5):653-664; Doi: 10.1007/ s11136-010-9793-3

8. Basch E, Bennett AV. Patient-reported outcomes in clinical trials of rare diseases. Journal of general internal medicine. J Gen Intern Med. 2014; 29 Suppl3:S801-S803; Doi: 10.1007/s11606-014-2892-z

9. Myles PS, Weitkamp B, Jones K, Melick J, Hensen S. Validity and reliability of a postoperative quality of recovery score: the QoR-40. Br J Anaesth 2000; 84(1):11-15. 
10. Policy Department A: Economic and Scientific Policy. Differences in cost of and access to pharmaceutical products in the European Union. EU Commission, Directorate General Internal policies. 2011 ; 1-92.

11. European Commission. HTA network reflection paper on "synergies between regulatory and HTA issues on pharmaceuticals". 2016 ; 1-8.

12. Commission Expert Group on Safe and Timely Access to Medicines for Patients ("STAMP"). Repurposing of established medicines/ active substances. 2017.

13. WHO (World Health Organization). 2015 Global Survey on Health Technology Assessment by National Authorities. 1-40; 2015.

14. Antoñanzas F, Terkola R, Postma M. The Value of Medicines: A Crucial but Vague Concept. Pharmacoeconomics. 2016; 34(12):1227-1239; Doi:10.1007/s40273-016-0434-8

15. Thokala P, Devlin N, Marsh K, Baltussen R, Boysen M, Kalo Z, Et al Multiple Criteria Decision Analysis for Health Care Decision Making-
-An Introduction: Report 1 of the ISPOR MCDA Emerging Good Practices Task Force. Value Health. 2016; 19(1):1-13; Doi: 10.1016/j. jval.2015.12.003

16. Stegemann S, Ternik RL, Onder G, Khan MA, van Riet-Nales DA. Defining Patient Centric Pharmaceutical Drug Product Design. AAPS J. 2016; 18(5):1047-1055; Doi: 10.1208/s12248-016-9938-6

17. Allen JD, Stewart MD, Roberts SA, Sigal EV. The Value of Addressing Patient Preferences. Value Health. 2017; 20(2):283-285; doi: 10.1016/j.jval.2016.11.029

18. Armstrong MJ, Mullins CD. Value Assessment at the Point of Care: Incorporating Patient Values throughout Care Delivery and a Draft Taxonomy of Patient Values. Value Health. 2017; 20(2):292-295; Doi: 10.1016/j.jval.2016.11.008

19. Perfetto EM, Oehrlein EM, Boutin M, Reid S, Gascho E. Value to Whom? The Patient Voice in the Value Discussion. Value Health. 2017;20(2):286-291; Doi: 10.1016/j.jval.2016.11.014 